\title{
Haemophilus influenzae oral whole cell vaccination for preventing acute exacerbations of chronic bronchitis (Review)
}

Foxwell AR, Cripps AW, Dear KBG

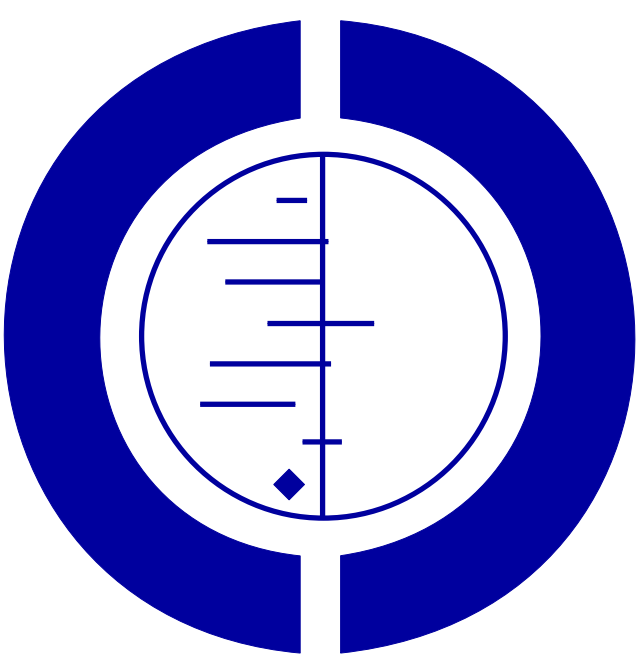

THE COCHRANE COLLABORATION $^{\circledR}$

This is a reprint of a Cochrane review, prepared and maintained by The Cochrane Collaboration and published in The Cochrane Library 2006, Issue 2

http://www.thecochranelibrary.com

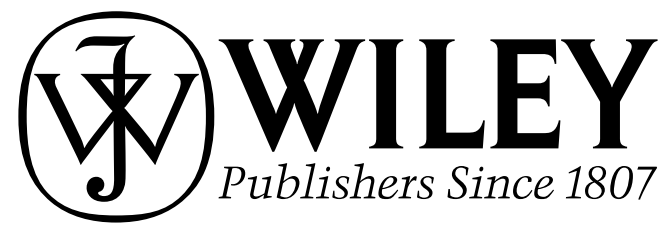

Haemophilus influenzae oral whole cell vaccination for preventing acute exacerbations of chronic bronchitis (Review) Copyright $\odot 2006$ The Cochrane Collaboration. Published by John Wiley \& Sons, Ltd 


\section{TABLE OF CONTENTS}

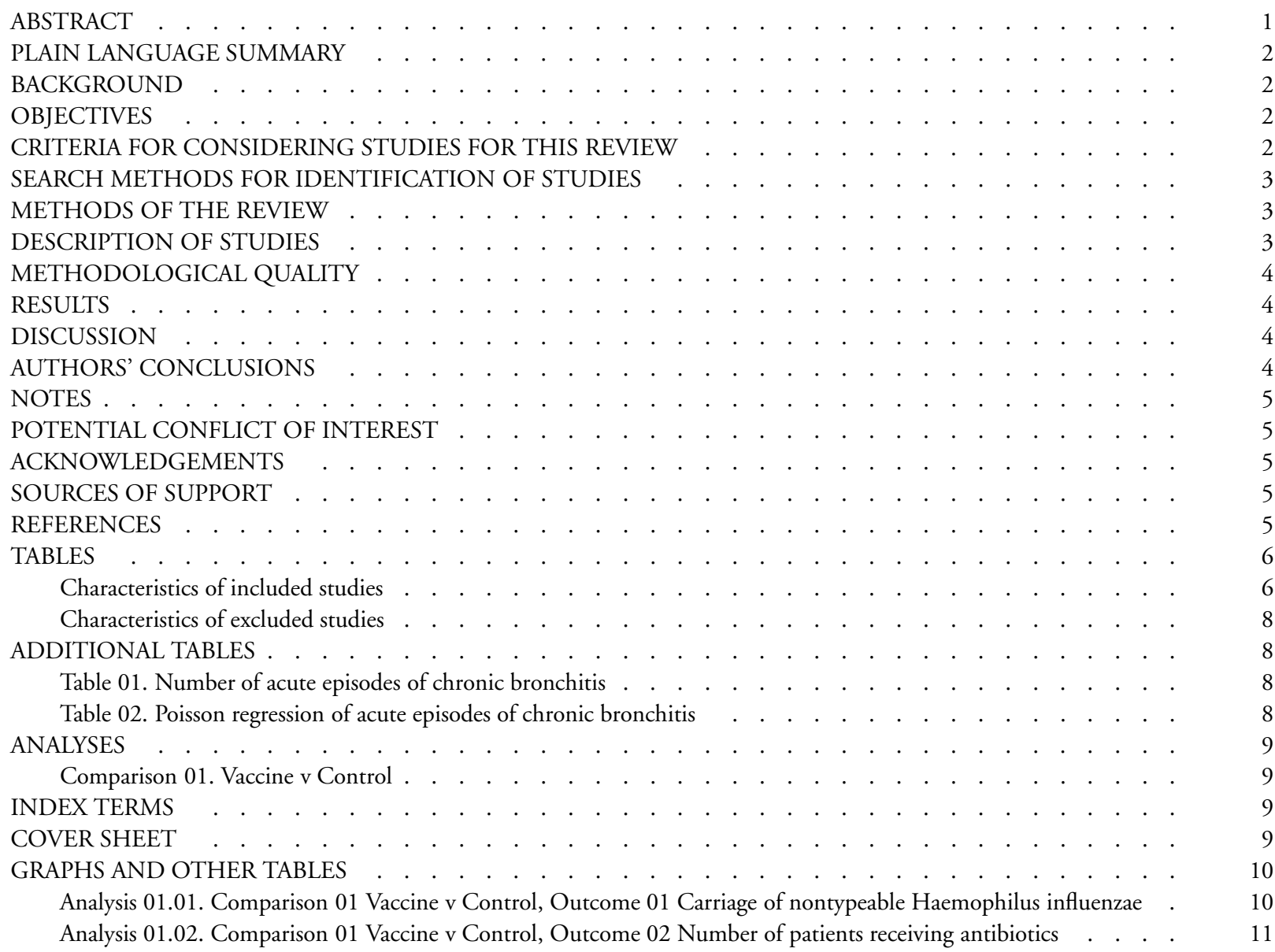

Haemophilus influenzae oral whole cell vaccination for preventing acute exacerbations of chronic bronchitis (Review) 


\title{
Haemophilus influenzae oral whole cell vaccination for preventing acute exacerbations of chronic bronchitis (Review)
}

\author{
Foxwell AR, Cripps AW, Dear KBG
}

This record should be cited as:

Foxwell AR, Cripps AW, Dear KBG. Haemophilus influenzae oral whole cell vaccination for preventing acute exacerbations of chronic bronchitis. The Cochrane Database of Systematic Reviews 2003, Issue 3. Art. No.: CD001958. DOI: 10.1002/14651858.CD001958.

This version first published online: 21 July 2003 in Issue 3, 2003.

Date of most recent substantive amendment: 28 May 2003

\section{A B S T R A C T}

\section{Background}

Acute bronchitis leading to ongoing exacerbations is a serious condition predisposed to by viruses or bacteria. It can be fatal. Antibiotic therapy has not been particularly useful in clearing bacteria such as nontypeable Haemophilus influenzae (NTHi) because they colonise the upper respiratory tract. An oral NTHi vaccine has been developed to protect against recurrent acute episodes in chronic bronchitis.

\section{Objectives}

To assess the effects of an oral whole cell nontypeable Haemophilus influenzae (NTHi) vaccine in protecting against recurrent acute episodes in chronic bronchitis.

\section{Search strategy}

We searched the Cochrane Central Register of Controlled Trials (CENTRAL) (issue 1, 2003); MEDLINE (1966 to 2003); EMBASE (1990 - 2003); Extramed (1994 to 2003); ISI Current Contents (1993 to 2003); Carl Uncover (1988 to 2003) and contacted investigators of the studies.

\section{Selection criteria}

Randomised trials comparing the effects of an oral monobacterial NTHi vaccine on patients with recurrent acute exacerbations of chronic bronchitis were included when there was overt matching of the vaccine and placebo groups on clinical grounds.

\section{Data collection and analysis}

Three reviewers extracted data and assessed trial quality independently from original records and publications for incidence and severity of bronchitis episodes and carriage rate of nontypeable Haemophilus influenzae measured in the upper respiratory tract every three months following vaccination.

\section{Main results}

Six trials were included in the study with a total of 440 participants. Oral vaccination using a monobacterial whole cell killed nontypeable Haemophilus influenzae significantly reduced the incidence of bronchitic episodes at three months after vaccination (Poisson rate ratio 0.666; $95 \%$ confidence interval $[\mathrm{CI}]$ 0.500, 0.887; $\mathrm{p}=0.005$ ) and perhaps at six months after vaccination (Poisson rate ratio 0.831; $95 \%$ CI $0.669,1.031 ; \mathrm{p}=0.093)$. The effect had disappeared by nine months. The severity of exacerbations in the treatment group, as measured by requirement to prescribe antibiotics, was likewise reduced by $58 \%$ at three months (Peto odds ratio $=0.42 ; 95 \% \mathrm{CI}$ $0.16,-1.13$ ), and by $65 \%$ at six months (Peto odds ratio $=0.35 ; 95 \%$ CI $0.16,-0.75$ ).

\section{Authors' conclusions}

Vaccination, in the autumn, of patients with recurrent acute exacerbations of chronic bronchitis reduced the number and severity of exacerbations over the winter months. A large clinical trial to assess longer term prognosis is needed. 


\section{PLAIN LANGUAGE SUMMARY}

Vaccination against acute exacerbations of chronic bronchitis in autumn reduces the number and severity of attacks during winter

Acute attacks of bronchitis often increase in frequency and severity during winter, especially among people who have chronic obstructive pulmonary disease (COPD) or chronic bronchitis. These winter attacks of bronchitis are commonly associated with nontypeable Haemophilus influenza (NTHi). The oral vaccine described in this review is of particular value due to its ability to decrease carriage of NTHi in the upper respiratory tract. The review of trials found that people with COPD or chronic bronchitis who were orally immunised in autumn had fewer and less severe attacks of bronchitis during the following winter. This effect was not long lasting.

\section{B A C K G R O U N D}

Acute exacerbations of bronchitis occur in people with compromised respiratory function. The etiology of the exacerbations remains a matter for debate with viruses and bacteria both being found to be definitive causative agents. The bacterial agents responsible for the acute exacerbations are often an expansion of the patient's own upper respiratory tract microbiota. The bacterial cause often reflects a particular balance of the host-parasite relationship involving an expanded bacterial flora within the bronchus lumen. Nontypeable Haemophilus influenzae (NTHi) is of particular importance in this scenario because of its frequent and predominant pattern of colonisation of the respiratory tract. NTHi infection usually remains mucosal.

In patients with chronic bronchitis and established obstructive lung disease, acute exacerbations of infection are a major cause of morbidity and mortality. Various treatment strategies have been attempted including immunostimulatory agents made from bacterial extracts, such as OM-85 BV and antibiotics. While OM-85 BV appears not to affect the occurrence of acute exacerbations of bronchitis, it does decrease the severity of the exacerbation (Collet 1997). Conventional antibiotic therapy has not been particularly helpful. This may well be due to the lack of ability to clear colonisers such as NTHi from the airways, hence, expansion of colonisation and chronic sepsis can be established (Murphy 1992; Van Alphen 1995; Foxwell 1998).

An alternative treatment strategy to antibiotics in patients 'at risk' of infection with NTHi, is to mucosally immunise. Following the development of successful vaccines for infections caused by Haemophilus influenzae (Hib), attention is now focused on NTHi, as immunity stimulated against the type-specific polysaccharide capsule of Hib has no ability to prevent infections caused by NTHi. Clinical trials have been conducted using the concept of oral immunisation against NTHi. The outcomes of these trials have been varied. This study evaluates oral immunisation trials against NTHi in an attempt to conclude whether or not a mucosal vaccine strategy is effective and worthy of further investigation.

\section{O B JE C T IVES}

The objectives of this review are:

1. to determine the effectiveness of an oral whole cell nontypeable Haemophilus influenzae (NTHi) vaccine in protecting against recurrent episodes of bronchitis;

2. to determine the relationship between vaccine efficacy and respiratory tract carriage of NTHi.

\section{CRITERIA FOR CONSIDERING STUDIES FOR THIS REVIEW}

\section{Types of studies}

All randomised controlled trials comparing the effects of an oral monobacterial NTHi vaccine on people predisposed to acute exacerbations of chronic bronchitis, with age-matched individuals receiving a placebo control.

\section{Types of participants}

All studies dealing with adults with either chronic obstructive pulmonary disease, or recurrent acute exacerbations of chronic bronchitis. As these conditions have been closely associated with high numbers of NTHi, the vaccine was considered to be relevant in looking at prevention of exacerbation frequency and severity.

\section{Types of intervention}

All trials comparing a monobacterial NTHi orally administered vaccine with a lactose placebo were included. Trials allowed the use of bronchodilators, analgesics and antibiotics to both active and placebo groups.

\section{Types of outcome measures}

The main outcomes of interest were:

1. incidence of acute exacerbations of chronic bronchitis;

2. carriage level of NTHi in the respiratory tract;

3. numbers of prescriptions for antibiotics in the trial and followup periods as an indication of severity of acute exacerbations. 


\section{SEARCH METHODS FOR IDENTIFICATIONOFSTUDIES}

See: Acute Respiratory Infections Group methods used in reviews.

Manual and computerised literature searches were used to identify all relevant published studies, with no language restrictions. An electronic search of the Cochrane Central Register of Controlled Trials (The Cochrane Library issue 1, 2003) was conducted, using similar search terms as those used to search MEDLINE (1966 to 2003):

\#1 explode 'Haemophilus-influenzae' / all subheadings in MIME,MJME

\#2 explode 'Vaccines-' / all subheadings in MIME,MJME

\#3 \#1 and \#2

\#4 explode 'Haemophilus-Vaccines' / all subheadings in

MIME,MJME

\#5 (h?emophilus adj influenz*) near vaccin*

\#6 \#3 or \#4 or \#5

\#7 explode 'Bronchitis-' / all subheadings in MIME,MJME

\#8 explode 'Bronchitis-Chronic' / all subheadings in

MIME,MJME

\#9 bronchit* $^{*}$

$\# 10$ \#7 or \#8 or \#9

$\# 11$ \#6 and \#10

An electronic search was also conducted on EMBASE (1990 to 2003); Extramed (1994 to 2003); ISI Current Contents (1993 to 2003); and Carl Uncover (1988 to 2003).

Manual data was sought by searching reference lists of trials and review articles; searching books related to respiratory tract infections, mucosal immunology or vaccines; searching abstracts from respiratory tract conferences, immunology conferences, microbiology conferences or vaccine conferences; and written enquiries to the authors of major relevant studies and experts in the field.

\section{METHODS OF THE REVIEW}

Two reviewers (RF, AC) independently selected the trials using the methods section of the study and without reference to the results, authors or journals. The methodological quality was assessed by/from details of randomisation, blinding of outcome assessment and of patients, and the number of patients lost to follow up. Disagreements were solved by discussion. No assumptions have been made that have not been statistically tested for by the authors of the original clinical trials. The ratio of males to females in each trial was very similar between the vaccinated and placebo groups. No attempt was made to ask whether the vaccine was better for one sex or the other. Similarly, no attempt has been made to distinguish between cultural backgrounds or the optimal age group for response to the vaccine. While these questions would be good to address, the lack of data across all the trials precludes analysis. All analysis was 'intent to treat', with further information being sought from authors of original studies when necessary. Each outcome measure compared between vaccinated and placebo groups was assessed for heterogeneity (the likelihood of the observed differences being due to a factor other than chance alone), using the RevMan software.

\section{DESCRIPTIONOFSTUDIES}

See Included Studies table and Excluded Studies table. Six clinical trials were conducted to test the efficacy of enteric coated, killed preparations of Haemophilus influenzae in populations prone to recurrent acute exacerbations of chronic bronchitis. The vaccine preparation and immunisation regime used in all trials consisted of three courses of 10 to the 11 th power formalin killed Haemophilus influenzae in enteric coated tablets taken on days 0, 28 and 56. Each course consisted of two tablets taken after breakfast over three consecutive days. In all cases, the placebo groups took enteric coated tablets containing glucose.

The trials varied in their length from three to 12 months duration. Randomisation of all the trails was achieved by a pharmacist preparing bottles of either active or placebo tablets. These bottles were numbered and randomised before being distributed to the clinicians involved in the trials. The pharmacist was responsible for breaking the randomised code at the conclusion of the trial period.

Trials varied slightly in their population groups, with trials one, two, three, four and six being taken from chronic bronchitics in Australia, with mean ages of 42 to 71 years. Trial five was conducted in chronic bronchitics in Papua New Guinea, with a mean age of 51 years.

Bacterial load was assessed by a standardised method throughout the six trials. Multiple cultures were performed on each person. In normal circumstances, the first culture following vaccination was taken at three months. Cultures were taken at regular 3 monthly intervals and extra cultures taken during illness. The method of obtaining the samples, transporting material and culture methods followed a set protocol. The only difference between the trials was in the method used to record the results, with absolute count and quadrant methods being used. Future trials should standardise all aspects of the measurement of bacterial load.

Measured outcomes in the trials were varied but included bacterial load within the respiratory tract, the number and severity of acute exacerbations and the usage of antibiotics. These outcomes were not always statistically useful. One trial was excluded from the study as there was no allowance made for a pre-trial period to randomise people showing differences in rates of infection, so the matching of placebo and vaccine groups could not be assessed. 
Corticosteroids were administered at a similar rate in both active and placebo groups. Antibiotics were prescribed in both arms of the trial according to standard clinical criteria. These included increase in volume and purulence of sputum, usually with increased breathlessness and sometimes fever. Standards were tight as the clinicians involved in the trials were following established procedures for respiratory medicine in Australia.

\section{METHODOLOG ICAL QUALITY}

All trials in this study were randomised controlled trials and fell into category A. Placebo and active preparations were randomly numbered by a pharmacist before being sent to clinicians involved with dispensing the preparations to trial participants. It was not until completion of the trial period that the pharmacist provided the list to allow decoding of the preparations and comparison with the data collected from the participants.

\section{R E S U L T S}

The total number of participants in the six analysed trials amount to 440. All participants were either male or female and aged between 19 and 93 years. They all had either chronic obstructive pulmonary disease, or recurrent acute exacerbations of chronic bronchitis. Patients were grouped and either treated with a placebo or a regime of whole cell killed preparations of Haemophilus influenzae.

The rate ratios $(95 \% \mathrm{CI})$ for acute infectious episodes of chronic bronchitis were estimated using a Poisson regression model including trial and treatment effects. Since the treatment effect was assumed to be the same for all trials, this was a fixed effects model. Table 01 shows the raw frequency data. Table 02 shows total bronchitic episodes in each arm and the results of Poisson regression models of protective effect (with ratios less than 1 indicating a protective effect of vaccination). Acute episodes of chronic bronchitis were significantly reduced in the vaccinated groups at three months after vaccination [rate ratio $0.666,95 \% \mathrm{CI}(0.500,0.887)]$ and were also reduced at six months $[0.831(0.669,1.031)]$ though the difference at six months was not significant at the $5 \%$ level. This effect had disappeared by nine months $[0.971(0.766,1.123)]$ and remained unapparent at 12 months $[1.005(0.750,1.350)]$.

In terms of the number of people needing to be vaccinated for prevention of a single episode, the data can be interpreted as follows. The estimated rate ratio is 0.666 (CI $0.5000,0.887$ ) for 0 to 3 months following vaccination. If one assumes a background rate of 0.6 episodes per person, this translates to a reduction of 1 episode for every 5 persons vaccinated (CI 3.3, 14.7). The rate for vaccine benefit reduces over time, as indicated in the previous paragraph.
Carriage of nontypeable Haemophilus influenzae was 32\% lower in the treatment group at three months (Peto odds ratio $=0.68$; $95 \%$ CI $0.41,1.11)$ and $43 \%$ lower in the treatment group at six months (Peto odds ratio $=0.57 ; 95 \%$ CI 0.32, 1.03). It returned to a similar level between the treatment and control group by nine months following vaccination.

The severity of exacerbations, as measured by the requirement to prescribe antibiotics, also favoured the treatment group at three months, with a $58 \%$ reduction in antibiotic usage (Peto odds ratio $=0.42 ; 95 \%$ CI $0.16,1.13)$, and at six months with a $65 \%$ reduction in antibiotic usage (Peto odds ratio $=0.35 ; 95 \%$ CI 0.16 , $0.75)$ following vaccination.

\section{I S C U S S I O N}

This review analysed six trials of monobacterial whole killed cell nontypeable Haemophilus influenzae vaccine in cases of multiple acute exacerbations of chronic bronchitis. The results support the use of the vaccine in reducing the number and severity of exacerbations within three to six months of vaccination.

Most of the studies were conducted with vaccination beginning in the autumn and thus reducing the exacerbations of bronchitis over winter. It would appear that the vaccine was not long lasting, with the control and treatment groups having similar incidence of exacerbations nine to 12 months following vaccination. If bronchitics with repeated exacerbations were to use this vaccine, at present the statistics show that a temporary reprieve from exacerbations would occur during winter.

The protocols used in the trials lack consistency in length of the trials, and thus, data at nine months and 12 months following vaccination could only be gleaned from two trials. There was doubt as to the ability to match people in the control and treatment groups for infectious episodes at the beginning of the trials. Many of the confidence intervals were wide due to the low numbers of reported incidences for data, such as patients requiring prescription of antibiotics. Data was also difficult to compare between trials due to the methods of reporting. This was particularly true when attempting to glean information on seasonal variability, and the severity of exacerbations.

\section{A U THORS' CONCLUSIONS}

\section{Implications for practice}

Vaccination of patients with recurrent acute exacerbations of chronic bronchitis who are vaccinated in the autumn will reduce the number and severity of exacerbations over the winter months. With realistic assumptions on background rates of bronchitic episodes, the results indicate that one episode of bronchitis will be prevented for every five individuals vaccinated. These 
results may be related to the higher level of bacterial colonisation during winter and care needs to be taken in presuming that the vaccine would be effective over a year.

\section{Implications for research}

There needs to be a large clinical trial into the long term effects of monobacterial whole killed cell nontypeable Haemophilus influenzae vaccine. It would be useful for this trial to assess both the outcome at 12 months and two years following vaccination. Careful standardisation of the protocols in terms of outcome measures in the areas of numbers of infectious episodes, severity of exacerbations, usage of antibiotics and carriage level of NTHi needs to be addressed. The concept of oral immunisation against nontypeable Haemophilus influenzae infection is worthy of further study. Broncho-Vascom (OM Pharma, Switzerland), a product containing lyophilised extracts of a number of bacteria, including Haemophilus influenzae, has been demonstrated to be efficacious through either reducing the number of acute upper respiratory tract infections or reducing the severity of acute bronchitic exacerbations in a number of infection situations where NTHi is acknowledged as one of the causative agents. However, these studies have not been accompanied by any comprehensive bacteriology to demonstrate the effect of this preparation on NTHi respiratory tract carriage.

\section{NOT E S}

This review was withdrawn after comments were received pointing out inconsistencies between the data and the text. The reviewers have completed their revisions and the review was re-published in issue 3, 2003.
Editors' note:

The Acute Respiratory Infections Group would like to thank Kristine Clement for reading and commenting on this review.

\section{POTENTIAL CONFLICTOF I N T EREST}

Professor Allan Cripps was involved in the initial animal work and conduct of the four trials in Newcastle, Australia. He is not employed by the commercialising company, has not received honoraria or participated in expert testimony on behalf of the commercialising company. However, he has undertaken a consultancy and had a small stock ownership in the commercialising company. The commercial product, 'Bronchostat', which was derived from the clinical trials assessed, is no longer commercially available.

\section{ACKNOW LEDGEMENTS}

The authors acknowledge the assistance of Anne Gallagher in the preparation of this review. This review was completed with the help of a Glaxo sponsored educational support grant from/through the Australasian Cochrane Centre.

\section{SOURCES OF S UPORT}

\section{External sources of support}

- No sources of support supplied

Internal sources of support

- No sources of support supplied

\section{R E F E R E N C E S}

\section{References to studies included in this review}

T1-83 Newcastle \{published and unpublished data\} Clancy R, Cripps A, Muree-Allen K, Yeung S, Engel M. Oral immunisation with killed Haemophilus influenzae for protection against acute bronchitis in chronic obstructive lung disease. Lancet 1985;1: $1395-7$.

Clancy R, Cripps A, Pang G, Yeung S, Murree-Allen K. The paradox of immunization against Haemophilus influenzae-related endobronchitis: protection restricted to ingestion of 'non-adjuvenated' vaccine. Advances in Experimental Medicine and Biology 1987;216B: 1759-64.

T2- 86 Newcastle \{published and unpublished data\} Clancy R, Cripps A, Gebski V. Protection against recurrent acute bronchitis after oral immunization with killed Haemophilus influenzae. Medical Journal of Australia 1990;152:413-6.
T3- 86 Newcastle \{published and unpublished data\}

Clancy R, Cripps A. Specific protection against acute bronchitis associated with nontypeable Haemophilus influenzae. Journal of Infectious Diseases 1992;165:S194-5.

T4- 87 Newcastle \{published and unpublished data\} Clancy R, Cripps A. Specific protection against acute bronchitis associated with nontypeable Haemophilus influenzae. Journal of Infectious Diseases 1992;165:S194-5.

T5- 87 Goroka, PNG \{published and unpublished data\} Lehmann D, Coakley K, Coakley C, Spooner V, Montgomery J, Michael A, et al. Reduction in the incidence of acute bronchitis by an oral Haemophilus influenzae vaccine in patients with chronic bronchitis in the highlands of Papua New Guinea. American Review of Respiratory Disease 1991;144:324-30.

T6- 88 Perth \{published and unpublished data\} Tandon M, Gebski V. A controlled trial of a killed Haemophilus 
influenzae vaccine for prevention of acute exacerbations of chronic bronchitis. Australian and New Zealand Journal of Medicine 1991;21: $427-32$.

\section{References to studies excluded from this review}

T7- 87 Glasgow

Cortecs International Limited, Deeside, UK 1987.

\section{Additional references}

Collet 1997

Collet JP, Shapiro S, Ernst P, Renzi P, Ducruet T, Robinson A, et al. Effects of an immunostimulating agent on acute exacerbations and hospitalizations in patients with chronic obstructive pulmonary disease. American Journal of Respiratory and Critical Care Medicine 1997;156:1719-24.

\section{Foxwell 1998}

Foxwell AR, Kyd J, Cripps A. Nontypeable Haemophilus influenzae:pathogenesis and prevention. Microbiology and Molecular Biology Reviews 1998;62:294-308.

\section{Murphy 1992}

Murphy T, Sethi S. Bacterial infection in chronic obstructive pulmonary disease. American Review of Respiratory Disease 1992;148: 1067-83.

\section{Van Alphen 1995}

Van Alphen L, Jansen H, Dankert J. Virulence factors in the colonization and persistence of bacteria in the airway. American Journal of Respiratory and Critical Care Medicine 1995;151:2094-2100.

T A B LE S

\section{Characteristics of included studies}

\begin{tabular}{|c|c|}
\hline Study & T1-83 Newcastle \\
\hline Methods & Randomised, double-blind, prospective, placebo-controlled study of three months duration over winter. \\
\hline Participants & $\begin{array}{l}50 \text { patients with chronic obstructive lung disease. } 33 \text { given a placebo, } 17 \text { vaccinated. Mean age } 62 \text {, sex ratio } \\
(\mathrm{m} / \mathrm{f}) 16 / 1 \text { for the placebo group and } 64.7 \text {, sex ratio } 14 / 3 \text { for the vaccine group. Many took antibiotics and } \\
\text { bronchodilators. Assume no drop-outs. }\end{array}$ \\
\hline Interventions & $\begin{array}{l}\text { Vaccine consisting of } 10 \text { to the } 11 \text { th formalin killed nontypeable Haemophilus influenzae in } 3 \text { courses of } \\
\text { enteric coated tablets given at days } 0,28 \text { and } 56 \text {. Each course consisted of two tablets given over three } \\
\text { consecutive days before breakfast. Placebos were enteric coated glucose tablets with or without sodium } \\
\text { tauroglycocholate. }\end{array}$ \\
\hline Outcomes & $\begin{array}{l}\text { No significant difference was found between placebo groups taking enteric coated tablets with or without } \\
\text { sodium tauroglycholate; therefore the two placebo groups were combined for the purpose of this study. }\end{array}$ \\
\hline \multirow[t]{2}{*}{ Notes } & Clancy et al. Lancet, 1985; 1: 1395-1397 \\
\hline & Clancy et al. Adv. Exp.Med.Bio. 1987: 216B: 1759-1764 \\
\hline Allocation concealment & A \\
\hline Study & T2- 86 Newcastle \\
\hline Methods & Randomised, double-blind, placebo-controlled study of six months duration including winter. \\
\hline
\end{tabular}




\section{Characteristics of included studies (Continued)}

Participants 40 patients with chronic bronchitis. 3 withdrawals, 2 from placebo and 1 from active treatment group.20 given a placebo, 20 vaccinated. Mean age 46.3, sex ratio (m/f) 8/12 for the placebo group and 47.4, sex ratio $11 / 9$ for the vaccine group.

Interventions Vaccine consisting of 10 to the 11th formalin killed nontypeable Haemophilus influenzae in 3 courses of enteric coated tablets given at days 0,28 and 56. Each course consisted of two tablets given over three consecutive days before breakfast. Placebos were enteric coated glucose tablets.

Outcomes

Notes Clancy et al. Medical Journal of Australia, 1990; 152:413-416

Allocation concealment A

\begin{tabular}{ll} 
Study & T3- 86 Newcastle \\
\hline Methods & Randomised, double-blind, placebo-controlled study of 12 months duration starting in March. \\
\hline Participants & $\begin{array}{l}109 \text { patients with chronic bronchitis. } 55 \text { given a placebo, } 54 \text { vaccinated. Mean age } 66.8, \text { sex ratio (m/f) } \\
44 / 11 \text { for the placebo group and } 64.5, \text { sex ratio } 41 / 13 \text { for the vaccine group. }\end{array}$ \\
\hline $\begin{array}{l}\text { Interventions } \\
\text { Vaccine consisting of } 10 \text { to the } 11 \text { th formalin killed nontypeable Haemophilus influenzae in } 3 \text { courses of } \\
\text { enteric coated tablets given at days } 0,28 \text { and } 56 . \text { Each course consisted of two tablets given over three } \\
\text { consecutive days before breakfast. Placebos were enteric coated glucose tablets. }\end{array}$ \\
\hline Outcomes & Clancy et al. Journal of Infectious Diseases, 1992; 165 (suppl):S194-S195 \\
\hline Notes & A
\end{tabular}

\begin{tabular}{ll} 
Study & T4- 87 Newcastle \\
\hline Methods & Randomised, double-blind, placebo-controlled study of 12 months duration starting in March. \\
\hline Participants & $\begin{array}{l}102 \text { patients with chronic bronchitis. } 49 \text { given a placebo, } 53 \text { vaccinated. Mean age 64.2, sex ratio (m/f) } \\
37 / 12 \text { for the placebo group and 65.8, sex ratio 43/10 for the vaccine group. }\end{array}$ \\
\hline Interventions & $\begin{array}{l}\text { Vaccine consisting of } 10 \text { to the } 11 \text { th formalin killed nontypeable Haemophilus influenzae in } 3 \text { courses of } \\
\text { enteric coated tablets given at days } 0,28 \text { and } 56 . \text { Each course consisted of two tablets given over three } \\
\text { consecutive days before breakfast. Placebos were enteric coated glucose tablets. }\end{array}$ \\
\hline Outcomes & Clancy et al. Journal of Infectious Diseases, 1992; 165 (suppl):S194-S195 \\
\hline Notes & A
\end{tabular}

\begin{tabular}{|c|c|}
\hline Study & T5- 87 Goroka, PNG \\
\hline Methods & Randomised, double-blind, prospective placebo-controlled study of 12 months duration starting in October. \\
\hline Participants & $\begin{array}{l}62 \text { patients with chronic bronchitis or }>2 \text { episodes of acute bronchitis in } 2 \text { years. } 32 \text { given a placebo, } 30 \\
\text { vaccinated. Mean age 53.7, sex ratio }(\mathrm{m} / \mathrm{f}) 15 / 17 \text { for the placebo group and } 52.6 \text {, sex ratio } 15 / 17 \text { for the } \\
\text { vaccine group: Drop-outs were } 11 \text { from vaccine group and } 4 \text { from placebo group. }\end{array}$ \\
\hline Interventions & $\begin{array}{l}\text { Vaccine consisting of } 10 \text { to the } 11 \text { th formalin killed nontypeable Haemophilus influenzae in } 3 \text { courses of } \\
\text { enteric coated tablets given at days } 0,28 \text { and } 56 \text {. Each course consisted of two tablets given over three } \\
\text { consecutive days before breakfast. Placebos were enteric coated glucose tablets. }\end{array}$ \\
\hline \multicolumn{2}{|l|}{ Outcomes } \\
\hline Notes & Lehman et al. American Review of Respiratory Disease, 1991; 144: 324-330. \\
\hline Allocation concealment & A \\
\hline
\end{tabular}


Characteristics of included studies (Continued)

Study T6- 88 Perth

\begin{tabular}{ll}
\hline Methods & Randomised, double-blind, placebo-controlled study of 12 months duration starting in March. \\
\hline Participants & $\begin{array}{l}77 \text { patients with chronic bronchitis. } 10 \text { were withdrawn (7 in placebo group and } 3 \text { in vaccine group). } 3 \\
\text { from the vaccine group died. } 33 \text { given a placebo, } 31 \text { vaccinated. Mean age } 71.1, \text { sex ratio (m/f) } 30 / 3 \text { for the } \\
\text { placebo group and } 73.1, \text { sex ratio } 22 / 9 \text { for the vaccine group. }\end{array}$ \\
\hline $\begin{array}{l}\text { Interventions } \\
\text { Vaccine consisting of } 10 \text { to the } 11 \text { th formalin killed nontypeable Haemophilus influenzae in } 3 \text { courses of } \\
\text { consecutive days before breakfast. Placebos were enteric coated glucose tablets. }\end{array}$ \\
\hline Outcomes & Tandon et al. Australian and New Zealand Journal of Medicine, 1991; 21:427-432 \\
\hline Notes & A \\
\hline Allocation concealment
\end{tabular}

\section{Characteristics of excluded studies}

T7-87 Glasgow There was no pre-trial assessment period to determine individual infection rates prior to vaccination.

A D D I T I O N A L TABLES

Table 01. Number of acute episodes of chronic bronchitis

\begin{tabular}{llllll} 
Trial number & $\mathbf{N}(\mathbf{v a c c}, \mathbf{c t r l})$ & $\mathbf{0 - 3}$ months & $\mathbf{0 - 6}$ months & $\mathbf{0 - 9}$ months & $\mathbf{0 - 1 2}$ months \\
T1 & \multicolumn{1}{c}{17,16} & 1,23 & \\
T2 & 19,18 & 10,17 & \\
T3 & 54,55 & 27,30 & 42,48 & 76,53 \\
T4 & 53,49 & 18,19 & 45,33 & 66,45 & 15,34 \\
T5 & 30,32 & 6,10 & 9,18 & 12,22 &
\end{tabular}

Table 02. Poisson regression of acute episodes of chronic bronchitis

$\begin{array}{lllll}\text { Time periods } & \text { Lumped rate: Vaccine } & \text { Lumped rate: Control } & \text { Rate ratio }(95 \% \text { CI) } & \text { p value } \\ 0-3 \text { months } & 78 / 185=0.422 & 118 / 185=0.638 & 0.666(.500, .887) & p=.005 \\ 0-6 \text { months } & 150 / 187=0.802 & 182 / 187=0.973 & 0.831(.669,1.031) & p=.093 \\ 0-9 \text { months } & 136 / 137=0.993 & 138 / 136=1.015 & 0.971(.766,1.23) & p=.81 \\ 0-12 \text { months } & 91 / 83=1.096 & 87 / 81=1.074 & 1.005(.750,1.350) & p=.97\end{array}$

Haemophilus influenzae oral whole cell vaccination for preventing acute exacerbations of chronic bronchitis (Review)

Copyright $(2006$ The Cochrane Collaboration. Published by John Wiley \& Sons, Ltd 
A N A L Y S E S

\section{Comparison 01. Vaccine v Control}

\begin{tabular}{|c|c|c|c|c|}
\hline Outcome title & $\begin{array}{l}\text { No. of } \\
\text { studies }\end{array}$ & $\begin{array}{c}\text { No. of } \\
\text { participants }\end{array}$ & Statistical method & Effect size \\
\hline $\begin{array}{l}01 \text { Carriage of nontypeable } \\
\text { Haemophilus influenzae }\end{array}$ & & & Peto Odds Ratio 95\% CI & Subtotals only \\
\hline $\begin{array}{l}02 \text { Number of patients receiving } \\
\text { antibiotics }\end{array}$ & & & Peto Odds Ratio 95\% CI & Subtotals only \\
\hline
\end{tabular}

\section{NDEXTERS}

\section{Medical Subject Headings (MeSH)}

Bronchitis [* prevention \& control]; Chronic Disease; *Haemophilus Vaccines; Randomized Controlled Trials; Recurrence [prevention $\&$ control]; Seasons

MeSH check words

Humans

\section{COVERSHEET}

Title

\section{Authors}

Contribution of author(s)

Issue protocol first published

Review first published

Date of most recent amendment

Date of most recent SUBSTANTIVE amendment

What's New

Date new studies sought but none found

Date new studies found but not yet included/excluded

Date new studies found and included/excluded

Date authors' conclusions section amended

Contact address
Haemophilus influenzae oral whole cell vaccination for preventing acute exacerbations of chronic bronchitis

Foxwell AR, Cripps AW, Dear KBG

AR Foxwell and AW Cripps provided expert opinion on the literature, inclusion and statistical analysis of the vaccine trials. KBG Dear provided expert opinion on statistical analysis of the vaccine trials and their meta-analysis.

$1998 / 3$

$2000 / 1$

17 February 2005

28 May 2003

Information not supplied by author

15 March 2003

Information not supplied by author

Information not supplied by author

Information not supplied by author

Dr Ruth Foxwell

Senior Lecturer

Gadi Research Centre

University of Canberra 
Canberra

ACT

2601

AUSTRALIA

E-mail: ruth.foxwell@canberra.edu.au

Tel: + 61262012089

DOI

10.1002/14651858.CD001958

Cochrane Library number

CD001958

Editorial group

Cochrane Acute Respiratory Infections Group

Editorial group code

HM-ARI

GRAPHS AND OTHER TABLES

\section{Analysis 0I.0I. Comparison 01 Vaccine v Control, Outcome 0 I Carriage of nontypeable Haemophilus} influenzae

Review: Haemophilus influenzae oral whole cell vaccination for preventing acute exacerbations of chronic bronchitis

Comparison: 01 Vaccine $v$ Control

Outcome: 0 I Carriage of nontypeable Haemophilus influenzae

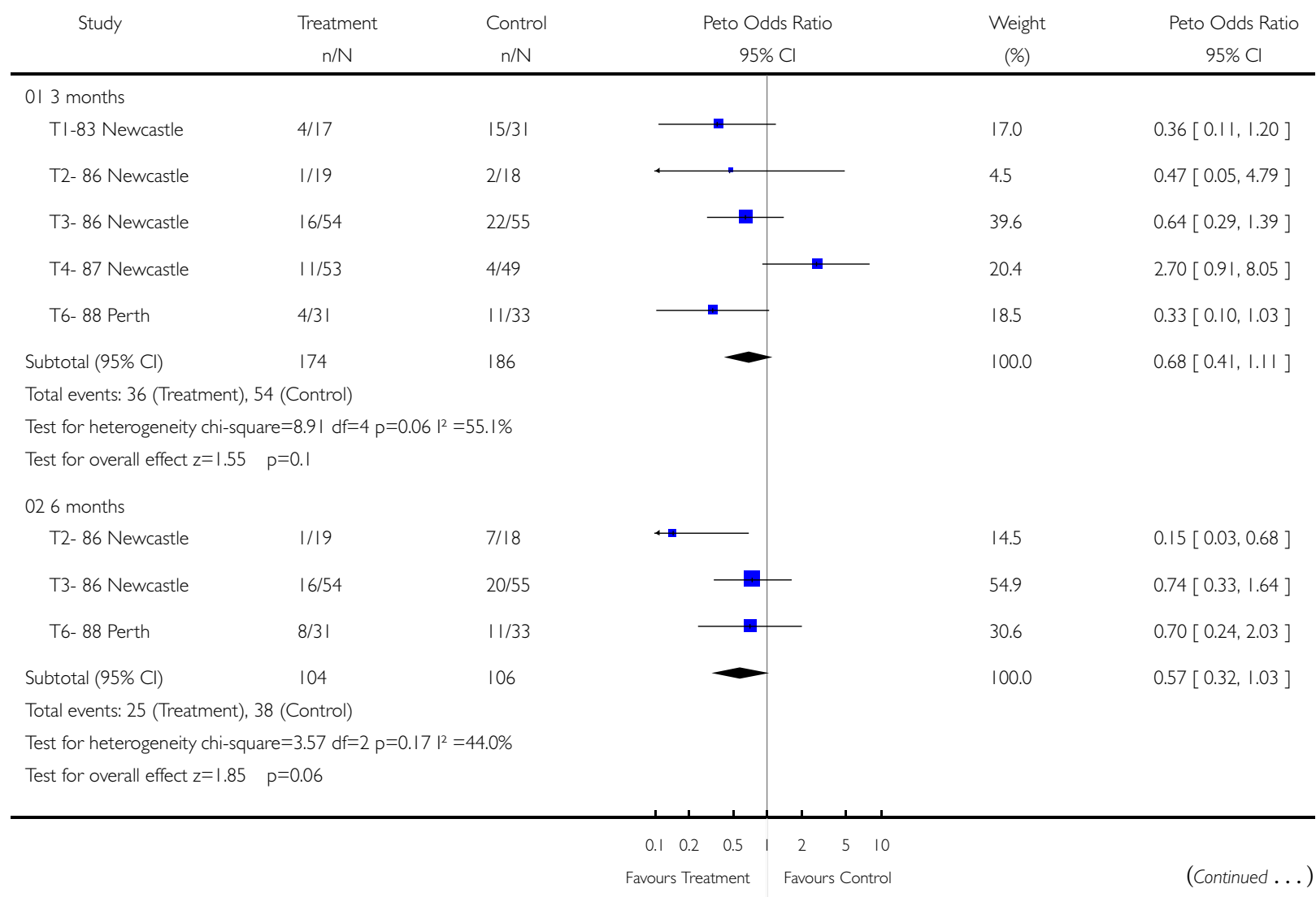

Haemophilus influenzae oral whole cell vaccination for preventing acute exacerbations of chronic bronchitis (Review) 


\begin{tabular}{|c|c|c|c|c|c|}
\hline Study & $\begin{array}{c}\text { Treatment } \\
\mathrm{n} / \mathrm{N}\end{array}$ & $\begin{array}{c}\text { Control } \\
n / N\end{array}$ & $\begin{array}{c}\text { Peto Odds Ratio } \\
95 \% \mathrm{Cl}\end{array}$ & $\begin{array}{c}\text { Weight } \\
(\%)\end{array}$ & $\begin{array}{c}\text { Peto Odds Ratio } \\
95 \% \mathrm{Cl}\end{array}$ \\
\hline \multicolumn{6}{|l|}{039 months } \\
\hline × T3- 86 Newcastle & 0/54 & $0 / 55$ & & 0.0 & Not estimable \\
\hline T4- 87 Newcastle & 9/53 & $0 / 49$ & & 100.0 & $8.09[2.07,31.59]$ \\
\hline Subtotal $(95 \% \mathrm{Cl})$ & 107 & 104 & & 100.0 & $8.09[2.07,31.59]$ \\
\hline \multicolumn{6}{|c|}{ Total events: 9 (Treatment), 0 (Control) } \\
\hline \multicolumn{6}{|c|}{ Test for heterogeneity: not applicable } \\
\hline Test for overall effect & $p=0.003$ & & & & \\
\hline
\end{tabular}

\section{Analysis 01.02. Comparison 01 Vaccine v Control, Outcome 02 Number of patients receiving antibiotics}

Review: Haemophilus influenzae oral whole cell vaccination for preventing acute exacerbations of chronic bronchitis Comparison: 01 Vaccine $\vee$ Control

Outcome: 02 Number of patients receiving antibiotics

\begin{tabular}{|c|c|c|c|c|c|}
\hline Study & $\begin{array}{c}\text { Treatment } \\
n / N\end{array}$ & $\begin{array}{l}\text { Control } \\
n / N\end{array}$ & $\begin{array}{c}\text { Peto Odds Ratio } \\
95 \% \mathrm{Cl}\end{array}$ & $\begin{array}{c}\text { Weight } \\
(\%)\end{array}$ & $\begin{array}{c}\text { Peto Odds Ratio } \\
95 \% \mathrm{Cl}\end{array}$ \\
\hline \multicolumn{6}{|l|}{013 months } \\
\hline T6- 88 Perth & $|4 / 3|$ & $22 / 33$ & & 100.0 & $0.42[0.16,1.13]$ \\
\hline Subtotal $(95 \% \mathrm{Cl})$ & 31 & 33 & & 100.0 & $0.42[0.16,1.13]$ \\
\hline \multicolumn{6}{|c|}{ Total events: I4 (Treatment), 22 (Control) } \\
\hline \multicolumn{6}{|c|}{ Test for heterogeneity: not applicable } \\
\hline \multicolumn{6}{|c|}{ Test for overall effect $z=1.72 \quad p=0.09$} \\
\hline \multicolumn{6}{|l|}{026 months } \\
\hline T2- 86 Newcastle & $5 / 19$ & $12 / 18$ & $\longleftarrow$ & 37.0 & $0.21[0.06,0.74]$ \\
\hline T6- 88 Perth & ||$/ 3 \mid$ & $18 / 33$ & & 63.0 & $0.47[0.18,1.25]$ \\
\hline Subtotal $(95 \% \mathrm{Cl})$ & 50 & 51 & & 100.0 & $0.35[0.16,0.75]$ \\
\hline \multicolumn{6}{|c|}{ Total events: I 6 (Treatment), 30 (Control) } \\
\hline \multicolumn{6}{|c|}{ Test for heterogeneity chi-square $=1.01 \mathrm{df}=\mid \mathrm{p}=0.32 \mathrm{l}^{2}=0.9 \%$} \\
\hline Test for overall effect z & 0.007 & & & & \\
\hline
\end{tabular}

$\begin{array}{lllllll}0.1 & 0.2 & 0.5 & 1 & 2 & 5 & 10\end{array}$

Favours Treatment Favours Control 